\title{
Cytosolic Calcium Oscillations in Astrocytes May Regulate Exocytotic Release of Glutamate
}

\author{
Lucia Pasti, ${ }^{1}$ Micaela Zonta, ${ }^{1}$ Tullio Pozzan, ${ }^{1}$ Stefano Vicini, ${ }^{2}$ and Giorgio Carmignoto ${ }^{1}$ \\ ${ }^{1}$ Department of Experimental Biomedical Sciences and Consiglio Nazionale delle Ricerche Center for the Study of \\ Biomembranes, University of Padova, 35121 Padova, Italy, and 2Department of Physiology and Biophysics, Georgetown \\ University, Washington, DC 20007
}

To obtain insights into the spatiotemporal characteristics and mechanism of $\mathrm{Ca}^{2+}$-dependent glutamate release from astrocytes, we developed a new experimental approach using human embryonic kidney (HEK) 293 cells transfected with the NMDA receptor (NMDAR), which act as glutamate biosensors, plated on cultured astrocytes. We here show that oscillations of intracellular $\mathrm{Ca}^{2+}$ concentration $\left(\left[\mathrm{Ca}^{2+}\right]_{\mathrm{i}}\right)$ in astrocytes trigger synchronous and repetitive $\left[\mathrm{Ca}^{2+}\right]_{\mathrm{i}}$ elevations in sensor $\mathrm{HEK}$ cells, and that these elevations are sensitive to NMDAR inhibition. By whole-cell patch-clamp recordings, we demonstrate that the activation of NMDARs in HEK cells results in inward currents that often have extremely fast kinetics, comparable with those of glutamate-mediated NMDAR currents in postsynaptic neurons. We also show that the release of glutamate from stimulated astrocytes is drastically reduced by agents that are known to reduce neuronal exocytosis, i.e., tetanus toxin and bafilomycin $A_{1}$. We conclude that $\left[\mathrm{Ca}^{2+}\right]_{i}$ oscillations represent a frequency-encoded signaling system that controls a pulsatile release of glutamate from astrocytes. The fast activation of NMDARs in the sensor cells and the dependence of glutamate release on the functional integrity of both synaptobrevin and vacuolar $\mathrm{H}^{+}$ ATPase suggest that astrocytes are endowed with an exocytotic mechanism of glutamate release that resembles that of neurons.

Key words: glia; calcium oscillations; transmitter release; exocytosis; SNARE protein; green fluorescent protein
Astrocytes can synthesize and release a large number of neuroactive compounds, including peptides, eicosanoids, and neurotrophins (Martin, 1992). The recent observation that astrocytes can also release neurotransmitters, such as the excitatory amino acid glutamate (Parpura et al., 1994), has attracted considerable interest for the possible involvement of glial cells in the modulation of neuronal function (Smith, 1994; Pfrieger and Barres, 1996). Furthermore, over the past decade, a growing body of evidence has emerged on the existence in the brain of a close bidirectional communication between neurons and astrocytes that may affect neuronal excitability and synaptic transmission. The existence of a signaling pathway from neurons to astrocytes was demonstrated by the observation that glutamate released from synaptic terminals after episodes of intense neuronal activity can activate metabotropic glutamate receptors (mGluRs) in the astrocyte membrane and trigger repetitive elevations in intracellular $\mathrm{Ca}^{2+}$ $\left(\left[\mathrm{Ca}^{2+}\right]_{\mathrm{i}}\right)$ (Dani et al., 1992; Porter and McCarthy, 1996; Pasti et al., 1997). Interestingly, an increase in the firing rate of neuronal afferents results in an increased frequency of $\left[\mathrm{Ca}^{2+}\right]_{i}$ oscillations

\footnotetext{
Received Aug. 9, 2000; revised Oct. 18, 2000; accepted Oct. 20, 2000.

This work was supported by Grants 845 and 850 from the Armenise-Harvard University Foundation, the Italian University and Health Ministries, the Italian Association for Cancer Research, Human Frontier Science Program Grant RG520/ 95, and Telethon-Italy Grants 845 and 850 (T.P.) and 1095 (G.C.). We thank P. Magalhães and C. Angulo for helpful discussion and critical reading of this manuscript and M. Nowycky and D. Janigro for critical reading of an early version of this manuscript, C. Montecucco and O. Rossetto for the gift of purified tetanus toxin and antibodies for synaptobrevin, and R. Pellizzari for collaborating in the immunoblotting experiments.

Correspondence should be addressed to Giorgio Carmignoto, Consiglio Nazionale delle Ricerche Center for the Study of Biomembranes and Department of Experimental Biomedical Sciences, University of Padova, Via G. Colombo 3, 35121 Padova, Italy. E-mail: gcarmi@civ.bio.unipd.it.

Copyright (C) 2001 Society for Neuroscience 0270-6474/01/210477-08\$15.00/0
}

in astrocytes (Pasti et al., 1997), demonstrating that the frequency of oscillations is under the dynamic control of neuronal activity and raising the possibility that it represents the code for the transfer of information from neurons to astrocytes. However, astrocytes can also signal back to neurons. In fact, astrocyte $\left[\mathrm{Ca}^{2+}\right]_{i}$ elevations can induce the release of glutamate which causes $\left[\mathrm{Ca}^{2+}\right]_{\mathrm{i}}$ elevations in adjacent neurons both in culture (Parpura et al., 1994; Hassingher et al., 1995) and in acute brain slices (Pasti et al., 1997). The release of glutamate from astrocytes was recently shown to modulate synaptic transmission in cultured hippocampal neurons (Araque et al., 1998a,b) as well as in the intact retina (Newman and Zahs, 1998). A physiologically relevant phenomenon, such as the activity-dependent potentiation of inhibitory synaptic transmission in the hippocampus between interneurons and pyramidal neurons, is critically dependent on glutamate release from astrocytes (Kang et al., 1998). The intracellular signaling transduction pathway mediating $\mathrm{Ca}^{2+}$ dependent glutamate release from astrocytes is still poorly defined. We recently found that activation of the mGluR in astrocytes from acute brain slices can trigger the release of glutamate from these cells (Pasti et al., 1997), whereas its coactivation with the AMPA receptor in cultured astrocytes powerfully enhanced the release through a signaling transduction system involving prostaglandin formation (Bezzi et al., 1998).

Although it has been demonstrated that astrocytes are capable of releasing glutamate, through the reverse operation of the glutamate transporter (Szatkowski et al., 1990) or by a swellinginduced mechanism (Kimelberg et al., 1990), none of these mechanisms accounts for the $\mathrm{Ca}^{2+}$-dependent release of glutamate triggered by stimuli such as bradykinin, agonists of AMPA/ mGluRs, and prostaglandins (Parpura et al., 1994; Bezzi et al., 
1998; Araque et al., 2000). To further explore the mechanism and spatiotemporal features of glutamate release from astrocytes, we devised a new experimental approach. HEK cells were cotransfected with the NMDA receptor and green fluorescent protein (GFP). Whereas the latter enables the positive identification of transfected cells, the former renders these cells sensitive to glutamate. When plated onto cultured astrocytes, the cotransfected cells act as biosensors for glutamate release from the astrocytes. By combining different experimental approaches, we demonstrate that $\left[\mathrm{Ca}^{2+}\right]_{\mathrm{i}}$ oscillations mediated by activation of AMPA/ mGluRs trigger in astrocytes a pulsatile, most likely vesiclemediated, release of glutamate.

Part of this work has been reported in abstract form (Carmignoto et al., 1999)

\section{MATERIALS AND METHODS}

Tissue preparations. Primary cultures of cortical astrocytes were prepared from neonatal Wistar rats as previously described (Pasti et al., 1995). For purification of the astrocyte culture, $14 \mathrm{~d}$ after plating, cells were subjected to $12 \mathrm{hr}$ of continuous shaking and then incubated for 5 min with $0.2 \%$ trypsin. Detached cells were then collected and replated on 24mm-diameter coverslips. Human embryonic kidney (HEK) 293 cells (American Type Culture Collection, Manassas, VA) were cotransfected with cDNAs encoding NMDAR subunits 1-2A (Vicini et al., 1998) and GFP (Prasher et al., 1992; Rizzuto et al., 1995), in the presence of $2 \mathrm{~mm}$ kynurenic acid and $500 \mu \mathrm{M}$ ketamine (Vicini et al., 1998); these cells will be henceforth referred to as NR-GFP cells. Cells were trypsinized 12-16 $\mathrm{hr}$ after transfection and replated on 2-week-old astrocyte secondary cultures. For confocal microscope experiments, after 1-3 d, both types of cells were loaded with the $\mathrm{Ca}^{2+}$ indicator indo-1. SDS-PAGE and immunoblotting were performed according to standard procedures (Laemmli, 1970; Rossetto et al., 1996). Proteins (50 $\mu \mathrm{g} / \mathrm{lane})$ were loaded on SDS-PAGE and transferred to nitrocellulose. Purified TeNT and antibodies against synaptobrevin (Rossetto et al., 1996) were kindly provided by O. Rossetto (Department of Experimental Biomedical Sciences, University of Padova, Padova, Italy). Antibodies against the glial fibrillar acidic protein (GFAP) and bafilomycin A1 were from Boehringer Mannheim (Indianapolis, IN) and Sigma (St. Louis, MO), respectively.

Confocal microscopy. Digital fluorescence microscopy (Nikon, RCM8000) was used for monitoring the change in indo- 1 emission after cell loading with indo-1/AM (Molecular Probes, Eugene, OR) as previously described (Pasti et al., 1997). After excitation at $351 \mathrm{~nm}$ wavelength, the emitted light was separated into its two components (405 and $485 \mathrm{~nm})$, and the ratio (405/485) was displayed as a pseudocolor scale. During experiments, cultured cells were continuously perfused (1.5-3 $\mathrm{ml} / \mathrm{min}$ ) at room temperature with a $\mathrm{Mg}^{2+}$-free extracellular solution consisting of (in mM): $145 \mathrm{NaCl}, 5 \mathrm{KCl}, 2 \mathrm{CaCl}_{2}, 1 \mathrm{Na}_{3} \mathrm{PO}_{4}, 5.5$ glucose, 0.01 glycine, and 10 HEPES, $\mathrm{pH} 7.4$, with $\mathrm{NaOH}$. Sampling rate was 2 sec, and 16 images were averaged for each frame. Occasionally, very bright fluorescent NR-GFP cells were apparently less loaded with Indo-1. Fluorescent resonant energy transfer between GFP and Indo-1, and/or inner filtering effect may account for this observation; the $405 / 485 \mathrm{~nm}$ ratio obtained in basal and stimulating conditions was not significantly affected by this phenomenon, and stimulated ratio was, however, not significantly changed. Calibration was performed intracellularly as described (Scheenen et al., 1998).

Patch-clamp recordings and analysis. Cells were viewed with an upright Axioskop FS microscope (Zeiss, Oberkochen, Germany) equipped with differential interference contrast Nomarski optics and an electrically insulated water immersion $40 \times$ objective with a long working distance $(2$ $\mathrm{mm})$. Standard procedures for pipette preparation and patch-clamp recordings in the whole-cell configuration were used (Hamill et al., 1981). In brief, electrodes were pulled in two stages on a vertical pipette puller from borosilicate glass capillaries (Wiretrol II; Drummond, Broomall, PA). Typical pipette resistance was 5-8 M . The recording pipette contained (in mM): $145 \mathrm{CsCl}, 2 \mathrm{MgCl}_{2}, 10$ EGTA, $3 \mathrm{Na}_{2}$ ATP, and 10 HEPES, pH 7.2, with $\mathrm{CsOH}$. Experiments were performed at room temperature, and cells were continuously perfused $(1.5-3 \mathrm{ml} / \mathrm{min})$ with the same solution used in the confocal microscope experiments (see above). To stimulate glutamate release from astrocytes, 10 or $20 \mu \mathrm{M}$ L-quisqualate (at the concentration more effective in eliciting oscillations in parallel experiments at the confocal microscope) was added to the perfusate. Recordings were performed in voltage clamp with an Axopatch-200B amplifier (Axon Instruments, Foster City, CA), sampled at 10 or $20 \mathrm{kHz}$, filtered at $1-2 \mathrm{kHz}$, and digitized by the interface Digidata1200A and pClamp 8 software (Axon Instruments). Off-line data analysis, curve fitting, and figure preparation were performed with Clampfit-8 (Axon Instruments) and Origin 5 (Microcal Software, Northampton, MA) software. Rise times represent the time elapsed from 20 to $80 \%$ of the peak amplitude of the response. Fitting of decay times of currents recorded from $N R-G F P$ cells was performed using a simplex algorithm based on a least squares exponential fitting routine. Double exponential equations of the form $I(t)=I_{\mathrm{f}} \times \exp \left(-t / \tau_{\mathrm{f}}\right)+I_{\mathrm{s}} \times \exp (-t /$ $\tau_{\mathrm{s}}$ ), where $I_{\mathrm{f}}$ and $I_{\mathrm{s}}$ are the amplitudes of the fast and slow decay components, and $\tau_{\mathrm{f}}$ and $\tau_{\mathrm{s}}$ are their respective decay time constants used to fit the data. A comparison of the summed square deviation was used to estimate the quality of single versus double exponential fits. To compare decay time between different currents, we used a weighted mean decay time constant $\tau_{\mathrm{w}}=\left[I_{\mathrm{f}} /\left(I_{\mathrm{f}}+I_{\mathrm{s}}\right)\right] \times t_{\mathrm{f}}+\left[I_{\mathrm{s}} /\left(I_{\mathrm{f}}+I_{\mathrm{s}}\right)\right] \times t_{\mathrm{s}}$. Data values are expressed as mean \pm SEM. To investigate the possible presence of gap junction communication between astrocytes and transfected HEK cells, Lucifer yellow $(4 \mathrm{mg} / \mathrm{ml})$ was included in the patch pipette in some experiments.

\section{RESULTS \\ Calcium oscillations trigger a pulsatile release of glutamate}

Our experimental approach allowed us to monitor simultaneously both the agonist-mediated $\left[\mathrm{Ca}^{2+}\right]_{\mathrm{i}}$ oscillations in astrocytes and the release of glutamate. The latter could be detected as a $\left[\mathrm{Ca}^{2+}\right]_{\mathrm{i}}$ increase in NR-GFP cells caused by $\mathrm{Ca}^{2+}$ influx through glutamate-activated NMDARs. Activation of metabotropic glutamate receptors (mGluRs) and AMPA receptors with either L-quisqualate or the selective agonists 1-aminocyclopentane-1,3dicarboxylic acid ( $t$-ACPD) and AMPA was used to trigger $\left[\mathrm{Ca}^{2+}\right]_{\mathrm{i}}$ oscillations in astrocytes. Stimulation of wild-type HEK cells (plated alone) with NMDA (200 $\mu \mathrm{M} ; n=67)$, AMPA (50 $\mu \mathrm{M} ; n=60), t$-ACPD $(100 \mu \mathrm{M} ; n=55)$, or L-quisqualate $(30 \mu \mathrm{M}$; $n=36)$ failed to evoke any $\left[\mathrm{Ca}^{2+}\right]_{\mathrm{i}}$ increase. On the contrary, $N R$-GFP cells plated alone displayed large $\left[\mathrm{Ca}^{2+}\right]_{\mathrm{i}}$ increases after NMDA but not L-quisqualate or $t$-ACPD/AMPA.

Figure 1 shows a typical example of the results obtained by stimulating $\left[\mathrm{Ca}^{2+}\right]_{\mathrm{i}}$ oscillations in astrocytes. NR-GFP cells plated onto astrocytes could be easily recognized by both their GFP fluorescence (Fig. 1 $A a$ ) and their response to NMDA (Fig. $1 A b)$. Stimulation with $3 \mu \mathrm{M}$ L-quisqualate induced in one of the astrocytes two successive $\left[\mathrm{Ca}^{2+}\right]_{\mathrm{i}}$ elevations (Fig. $1 A c, d$ ). The $\left[\mathrm{Ca}^{2+}\right]_{\mathrm{i}}$ change initiated at the level of the process (spot 1) and then spread to the soma (spot 2; Fig. $1 \mathrm{Ac}$ ). In the NR-GFP cells close to the stimulated astrocyte, $\left[\mathrm{Ca}^{2+}\right]_{\mathrm{i}}$ elevations synchronous with those occurring in the astrocyte were observed. The response in NR-GFP cells was attributable to activation of the NMDAR because it was abolished by the NMDAR antagonist D-2-amino-5-phosphonopentanoic acid (D-AP-5; Fig. $1 B$ ). The $\left[\mathrm{Ca}^{2+}\right]_{\mathrm{i}}$ rise in $N R-G F P$ cells (spots 3 and 4 ) initiated concurrently with the $\left[\mathrm{Ca}^{2+}\right]_{\mathrm{i}}$ peak in the process and before that in the soma (Fig. $1 A c, A d, B$, inset), suggesting that the site of glutamate release is localized at the level of the process. We analyzed a total of $52 \mathrm{NR}-G F P$ cells that displayed $\left[\mathrm{Ca}^{2+}\right]_{\mathrm{i}}$ elevations after either $t$-ACPD/AMPA or L-quisqualate-induced $\left[\mathrm{Ca}^{2+}\right]_{\mathrm{i}}$ oscillations in astrocytes: $87.2 \%$ (82 of 94 ) of D-AP-5-sensitive $\left[\mathrm{Ca}^{2+}\right]_{\mathrm{i}}$ transients occurred in temporal correlation with a $\left[\mathrm{Ca}^{2+}\right]_{\mathrm{i}}$ transient in nearby astrocytes. After the wash-out of D-AP-5, in all cells tested $(n=3)$, we observed a full recovery of the response to L-quisqualate. The $\left[\mathrm{Ca}^{2+}\right]_{\mathrm{i}}$ rise in $N R-G F P$ cells could not be attributed to gap junction communication between astrocytes and $N R$-GFP cells because Lucifer yellow included in a patch pipette 

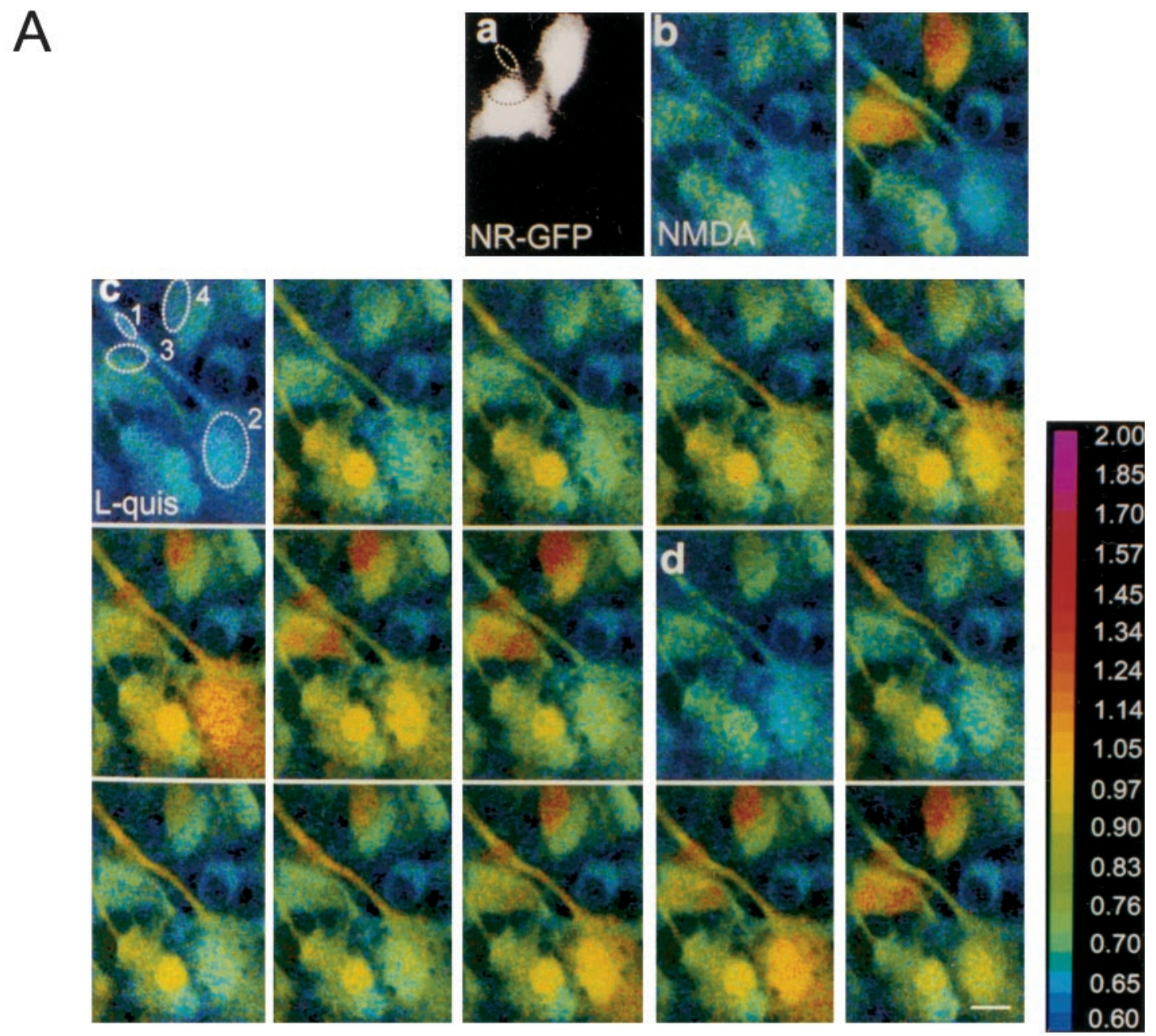

B
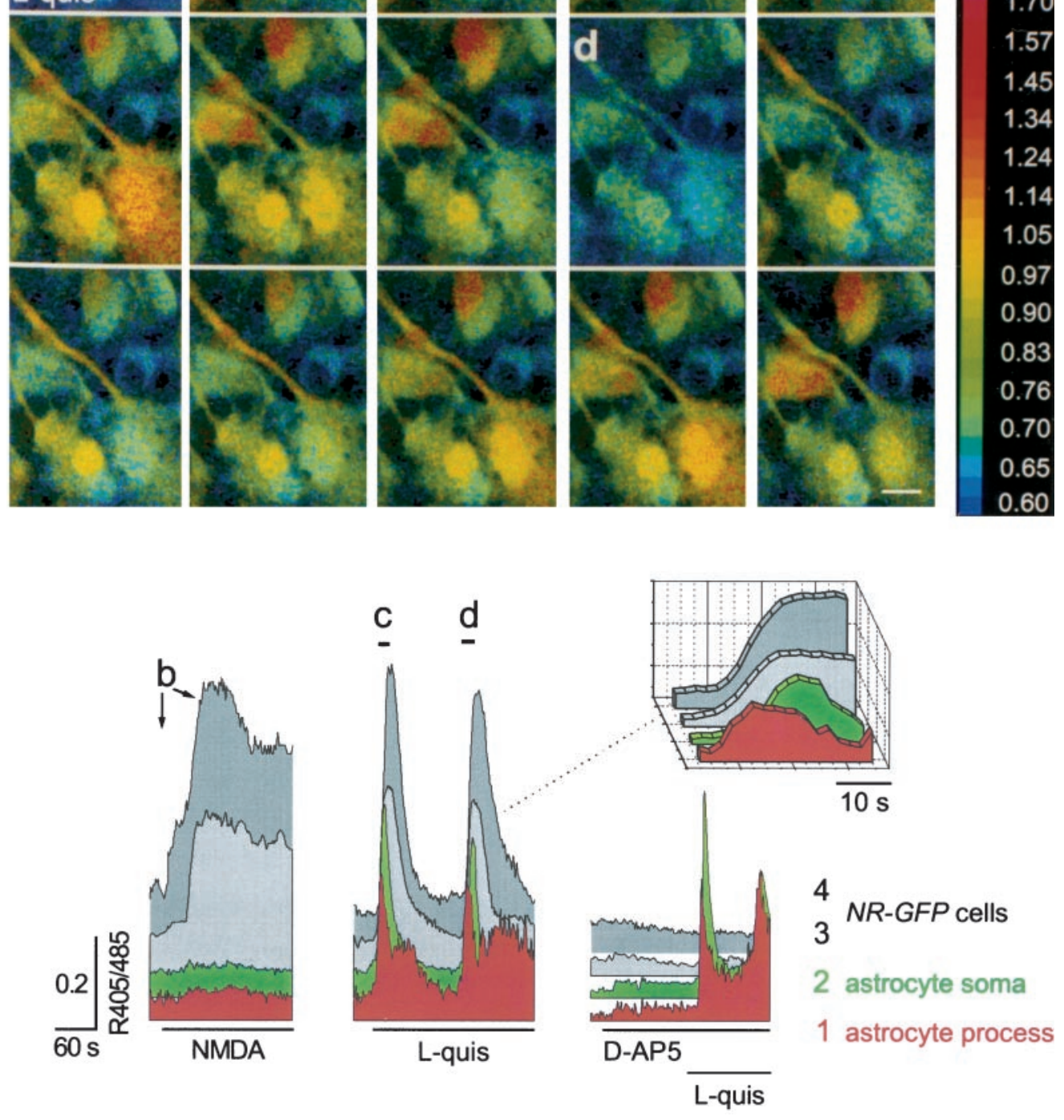

Figure 1. $\left[\mathrm{Ca}^{2+}\right]_{\mathrm{i}}$ oscillations trigger synchronous $\left[\mathrm{Ca}^{2+}\right]_{\mathrm{i}}$ elevations in sensor cells. $A$, Four $N R$ - $G F P$ cells, identified by their GFP fluorescence at 488 $\mathrm{nm}$ excitation wavelength $(a)$, but not astrocytes, display $\left[\mathrm{Ca}^{2+}\right]_{\mathrm{i}}$ elevations after $100 \mu \mathrm{M}$ NMDA stimulation $(b)$. $c, d$, Sequence of pseudocolor images showing the $\left[\mathrm{Ca}^{2+}\right]_{\mathrm{i}}$ changes after stimulation with $3 \mu \mathrm{M}$ quisqualate in one astrocyte (spot 2), its process (spot 1 ), and in two of the NR-GFP cells (spots 3 and 4 ). Sampling rate, 2 sec. Scale bar, $10 \mu \mathrm{m}$. The ratio (405/485) is displayed as a pseudocolor scale. $B$, Kinetics of the $405 / 485$ changes from the

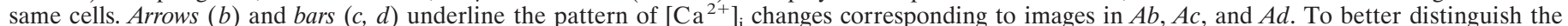
response from each cell, in this as well as in the other figures, traces are shifted on the $y$-axis. The onset of the $\left[\mathrm{Ca}^{2+}\right]_{\mathrm{i}} \mathrm{change}$ in $N R$-GFP cells clearly occurred after the $\left[\mathrm{Ca}^{2+}\right]_{i}$ elevation in the process and before that in the soma (see the three-dimensional inset reporting the responses at expanded time scale). Basal 405/485 values in astrocytes and NR-GFP cells were similar and ranged from 0.61 to 0.95 . After the wash-out of D-AP-5, in all cells tested $(n=3)$, we observed a full recovery of the response to L-quisqualate $(0.40 \pm 0.14$ and $0.42 \pm 0.12$, after the first and third challenge, respectively; mean $405 / 485$ change \pm SEM; relative change of response amplitude in the third with respect to the first challenge, $+6 \% ; n=3$ ). Two successive stimulations also elicited comparable responses $(0.49 \pm 0.12$ and $0.60 \pm 0.15 ;+22 \% ; n=4)$. 

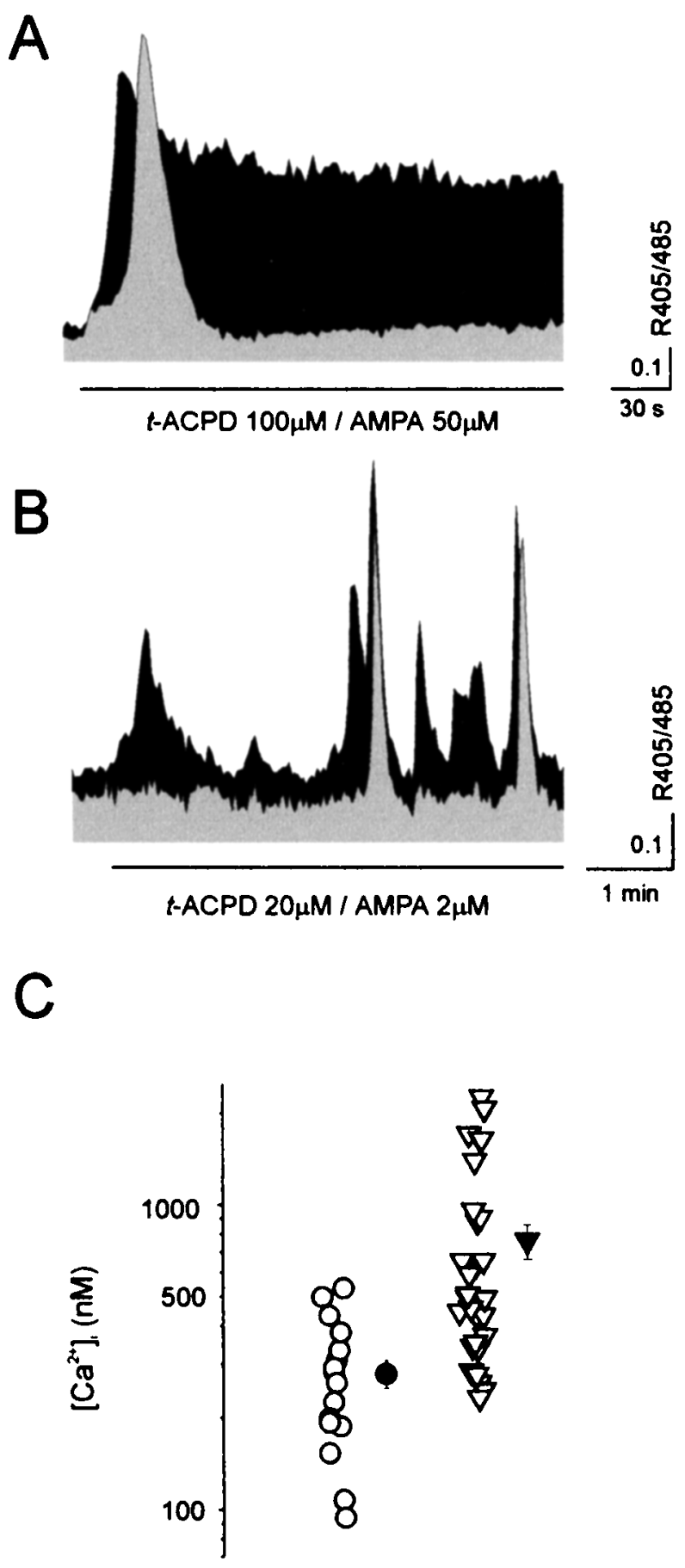

failure success

Figure 2. The glutamate-mediated response in NR-GFP cells depends on the pattern and amplitude of $\left[\mathrm{Ca}^{2+}\right]_{\mathrm{i}}$ oscillations. $A$, A sustained $\left[\mathrm{Ca}^{2+}\right]_{\mathrm{i}}$ increase in the astrocyte (black area) evokes only a single $\left[\mathrm{Ca}^{2+}\right]_{\mathrm{i}}$ transient in the adjacent NR-GFP cell ( gray area). B, Astrocyte $\left[\mathrm{Ca}^{2+}\right]_{i}$ peaks of large amplitudes resulted in synchronous $\left[\mathrm{Ca}^{2+}\right]_{\mathrm{i}}$ elevations in the $N R-G F P$ cell. $C$, Values of the astrocyte $\left[\mathrm{Ca}^{2+}\right]_{\mathrm{i}}$ peaks $(n=48)$ that failed (failure) or succeeded (success) to trigger a correlated $\left[\mathrm{Ca}^{2+}\right]_{\mathrm{i}}$ elevations in the NR-GFP cells. Only astrocytes displaying an oscillatory pattern comprised of both low- and large-amplitude $\left[\mathrm{Ca}^{2+}\right]_{i}$ peaks were considered $(n=13)$. The mean values of the $\left[\mathrm{Ca}^{2+}\right]_{\mathrm{i}}$ change from the two groups are significantly different $(280 \pm 30$ vs $764 \pm 100 \mathrm{nM} ; p<0.005$, one-way ANOVA). never diff used from patched NR-GFP cells $(n=10)$ to surrounding astrocytes or from patched astrocytes $(n=3)$ to NR-GFP cells. Taken together, the above results directly demonstrate that $\left[\mathrm{Ca}^{2+}\right]_{\mathrm{i}}$ oscillations in astrocytes, mediated by AMPA and mGlu receptors, lead to a pulsatile release of glutamate that triggers NMDAR-mediated $\left[\mathrm{Ca}^{2+}\right]_{\mathrm{i}}$ elevations in NR-GFP cells.

The dependence of the response of NR-GFP cells on the pattern of astrocyte $\left[\mathrm{Ca}^{2+}\right]_{i}$ oscillations was next investigated. Challenge with agonists of AMPA/mGlu receptors at high concentration, which induces a single $\left[\mathrm{Ca}^{2+}\right]_{\mathrm{i}}$ peak followed by a sustained plateau in astrocytes, triggers only a single $\left[\mathrm{Ca}^{2+}\right]_{\mathrm{i}}$ transient in the neighboring NR-GFP cells (Fig. $2 A$ ). A repetitive response in NR-GFP cells was never observed under these conditions. Furthermore, high- but not low-amplitude $\left[\mathrm{Ca}^{2+}\right]_{i}$ peaks in the astrocyte result in effective stimulation of $\left[\mathrm{Ca}^{2+}\right]_{i}$ changes in the adjacent $N R$-GFP cell (Fig. $2 B$ ). In Figure $2 C$ the amplitudes of the $\left[\mathrm{Ca}^{2+}\right]_{i}$ peaks in stimulated astrocytes are grouped according to the presence (success) or absence (failure) of response in nearby $N R-G F P$ cells. $\left[\mathrm{Ca}^{2+}\right]_{\mathrm{i}}$ peaks, measured at the soma, with amplitude of $>550 \mathrm{nM}$ always triggered a $\left[\mathrm{Ca}^{2+}\right]_{\mathrm{i}}$ increase in NR-GFP cells; below this value, successes were sometimes observed. Furthermore, we confirmed that prostaglandin formation represents a crucial step in the signaling transduction system regulating in astrocytes the $\mathrm{Ca}^{2+}$-dependent release of glutamate (Bezzi et al., 1998). NR-GFP cells $(n=8)$, which displayed $\left[\mathrm{Ca}^{2+}\right]_{\mathrm{i}}$ increases on a first AMPA/mGluRs stimulation, failed to respond to a second challenge after preincubation with $5 \mu \mathrm{M}$ indomethacin, an inhibitor of the prostaglandinforming enzyme cyclo-oxygenase. Finally, after depletion of $\mathrm{Ca}^{2+}$ from astrocyte intracellular stores by preincubation with 10 $\mu \mathrm{M}$ cyclopiazonic acid, activation of AMPA/mGluRs failed to trigger $\left[\mathrm{Ca}^{2+}\right]_{\mathrm{i}}$ changes in astrocytes, and no response was observed in NR-GFP cells $(n=11)$.

In $35 \%$ of $N R-G F P$ cells responsive to L-quisqualate stimulation of astrocytes, D-AP-5 was unable to block the $\left[\mathrm{Ca}^{2+}\right]_{i}$ increase, suggesting that astrocytes can release, besides glutamate, other agents that can trigger $\left[\mathrm{Ca}^{2+}\right]_{\mathrm{i}}$ elevations in $\mathrm{HEK}$ cells. Similarly, a number of nontransfected (GFP-negative) HEK cells (46 of $119 ; 38.6 \%$ ) also displayed $\left[\mathrm{Ca}^{2+}\right]_{i}$ elevations after astrocyte stimulation. The D-AP-5-insensitive responses in HEK cells were caused by the release from stimulated astrocytes of prostaglandins, most likely $\mathrm{PGE}_{2}$ (data not shown).

\section{On the mechanism of glutamate release from astrocytes}

The mechanism of glutamate release from activated astrocytes was next investigated. To this end we used the patch-clamp recording technique that ensures a higher temporal resolution of glutamate-mediated activation of NMDARs in NR-GFP cells. The rationale is as follows. If glutamate release occurs via an exocytotic mechanism, the resulting sudden increase of glutamate concentration in the proximity of the recorded NR-GFP cell should trigger a rapid activation of the NMDAR. Conversely, other release mechanisms (e.g., a carrier-mediated process), should generate much slower kinetics. Figure $3 A$ shows an $N R$ GFP cell plated on astrocytes and identified by its GFP fluorescence. After a challenge with L-quisqualate, this cell displayed pulsatile, inward current events that resemble NMDA EPSCs (Fig. 3B). Many currents had rise times as fast as a few milliseconds and decay time constants comparable with those of NMDA EPSCs (Collingridge et al., 1988; Lester et al., 1990; Carmignoto and Vicini, 1992) (Fig. 3C, events 1 and 2,D). Some events 
A B
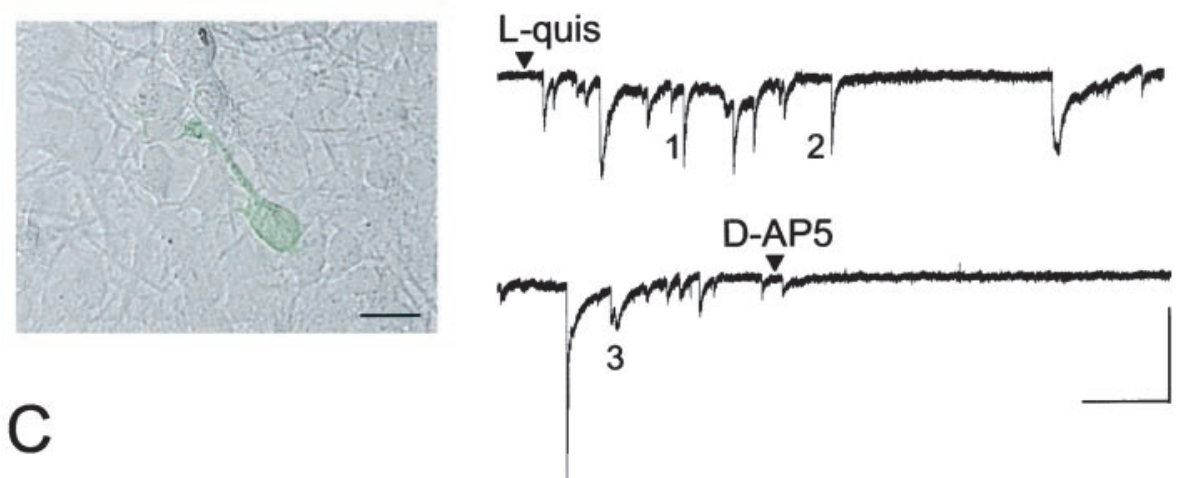
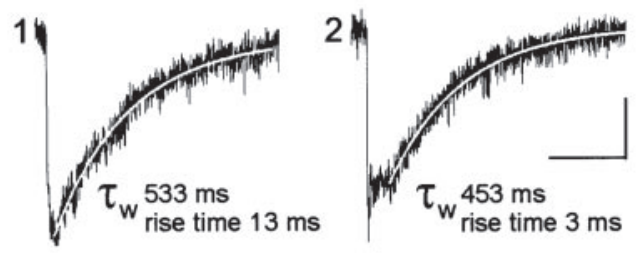

3

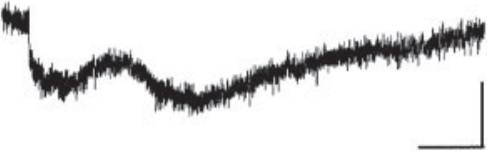

D

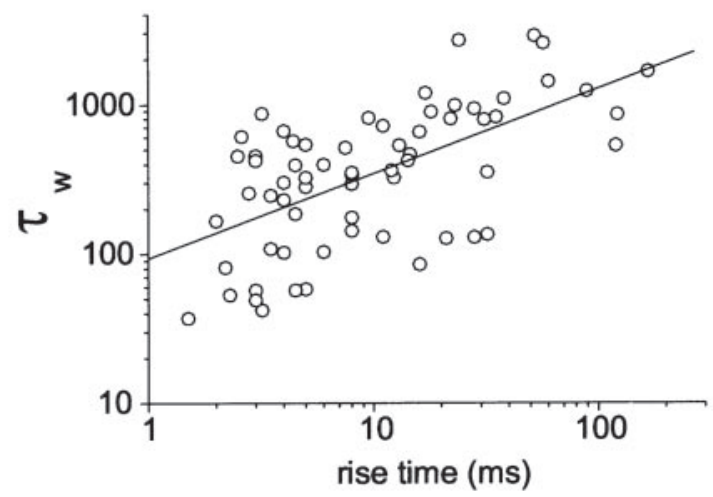

characterized by a peak followed by a sustained current (Fig. 3C, event 2), i.e., similar to those obtained by prolonged applications of NMDA in neurons (Lester and Jahr, 1992; Vicini et al., 1998), were occasionally observed. Currents with slower kinetics were also recorded (Fig. $3 C$, event 3). Currents with fast kinetics were observed in $13 N R$-GFP cells from a total of 52 recorded cells and were regularly blocked by $10 \mu \mathrm{M}$ D-AP-5. In Figure $3 D$ the rise time values of the currents recorded from NR-GFP cells are expressed as a function of the current decay time constant $\tau_{\mathrm{w}}$. The significant degree of correlation between these two values is noteworthy. Thirty-two cells of our sample displayed on astrocyte stimulation either very slow current events or repetitive episodes of noise increase resembling bursts of NMDAR channel openings. These types of response were also regularly blocked by D-AP-5 $(10 \mu \mathrm{M})$. No responses were observed in the remaining seven cells. In the absence of astrocytes, no inward currents were recorded from NR-GFP cells $(n=15)$ after stimulation with 20 $\mu \mathrm{M}$ L-quisqualate.

To provide further insights into the mechanism of glutamate release, astrocytes were incubated for $24 \mathrm{hr}$ with $100 \mathrm{~nm}$ tetanus neurotoxin (TeNT), a specific neurotoxin that blocks the exocytotic release of neurotransmitters. In neurons, the effects of TeNT depends on receptor-mediated endocytosis of the toxin followed
Figure 3. Stimulation of astrocytes results in glutamate-mediated, fast activation of NMDARs in the sensor cell. $A, N R-G F P$ cell plated on cultured astrocytes. Scale bar, $10 \mu \mathrm{m}$. B, The NR-GFP cell shown in $A$ responded with repetitive, inward currents after stimulation of astrocytes with $10 \mu \mathrm{M}$ quisqualate. Holding potential, $-55 \mathrm{mV}$. Calibration: $20 \mathrm{pA}, 10 \mathrm{sec} . C$, Events 1, 2, and 3 are reported at expanded scales. Calibration: $5 \mathrm{pA}, 500 \mathrm{msec}$. Rise time value of the current and decay time constant $\tau_{\mathrm{w}}$ of the curve best describing the decay are reported. The fitting curve (white line) is superimposed to the currents. $D$, Scatter plot of rise time values of the currents recorded from $13 N R-G F P$ cells expressed as a function of the current decay time constant $\tau_{\mathrm{w}}$ (mean \pm SEM; rise time, $20.2 \pm$ $3.75 \mathrm{msec}$; range, $1.5-167 \mathrm{msec} ; \tau_{\mathrm{w}} 563 \pm 74.9 \mathrm{msec}$; range, 37-2896 msec; amplitude, $20.2 \pm 6.7 \mathrm{pA}$; range, 3.2-272 pA; $n=65$ ). Very slow currents (rise and decay times $>200 \mathrm{msec}$ and $3 \mathrm{sec}$, respectively) such as event 3 , were not included in our sample. The line is the linear fit to the data $(r=0.61 ; p<$ 0.0001).

by release of the active subunit into the cytoplasm and proteolytic cleavage of the vesicle protein synaptobrevin (Schiavo et al., 1992). No inward current events were recorded from NR-GFP cells $(n=19)$ plated on TeNT-treated astrocytes and stimulated with L-quisqualate (Fig. 4A). Only in three cells were a few episodes of noise increase observed. The dramatic reduction of the response in NR-GFP cells after stimulation was accompanied by the cleavage of synaptobrevin, as demonstrated by the reduction in specific immunoreactivity in TeNT-treated astrocytes as compared with controls (Fig. 4B). The amplitude and pattern of L-quisqualate-induced $\left[\mathrm{Ca}^{2+}\right]_{i}$ oscillations were not affected by TeNT treatment (Fig. $5 A-C$ ). It should be noted that prolonged incubations with the toxins are necessary to inhibit glutamate release from astrocytes, whereas inhibition of presynaptic release of neurotransmitters is complete in $\sim 30$ min (Pasti et al., 1997; Bezzi et al., 1998).

We next investigated the effects of bafilomycin, a specific inhibitor of the vacuolar $\mathrm{H}^{+}$ATPase (v-ATPase) (Bowman et al., 1988; Stevens and Forgac, 1997), which blocks glutamate release in stimulated neurons (Araque et al., 2000; Zhou et al., 2000). By inhibiting $\mathrm{H}^{+}$pumping, this drug causes the collapse of the $\mathrm{H}^{+}$ gradient across the membrane that is necessary for the uptake of glutamate into the synaptic vesicle lumen (Maycox et al., 1990). In 


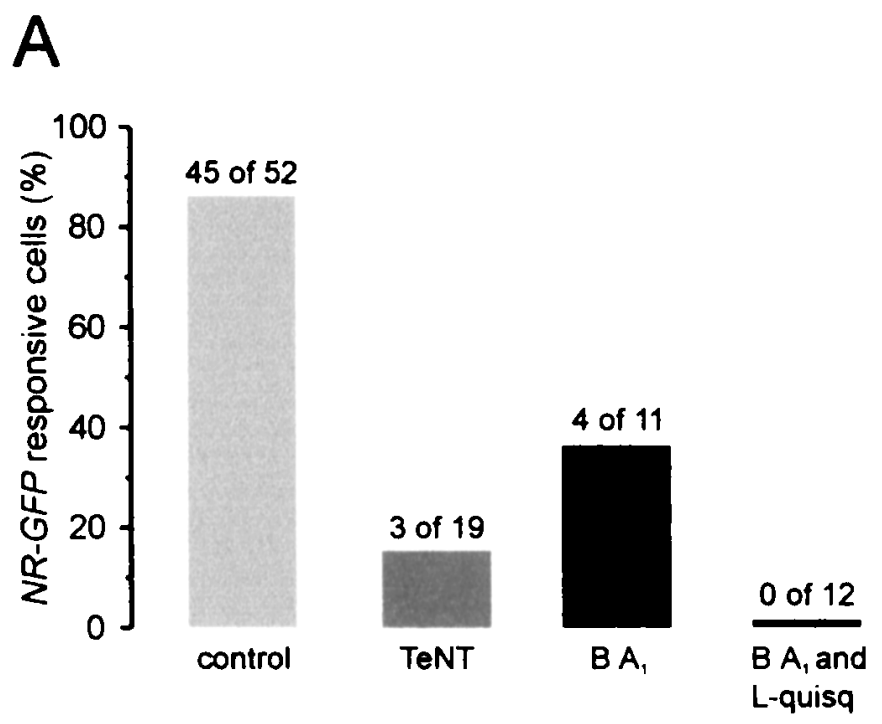

B

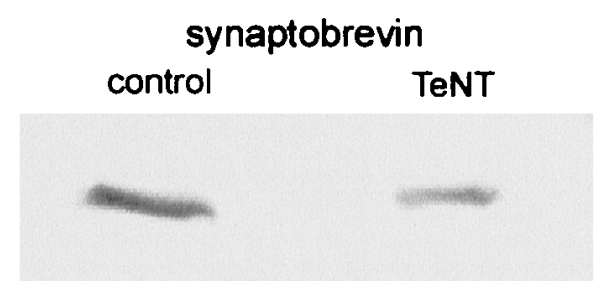

Figure 4. TeNT and bafilomycin $\left(\mathrm{BA}_{1}\right)$ reduce the response of NR-GFP cells. $A$, Histograms reporting the number and relative percentage of $N R-G F P$ cells responsive to astrocyte stimulation under different experimental conditions (see Results for details). $B$, Synaptobrevin immunoreactivity was reduced in Western blots of TeNT-treated astrocytes as compared with untreated astrocytes $(-47.5 \pm 6.3 \% ; n=2$; Gel Doc 2000 multianalyst densitometric assay; Bio-Rad, Hercules, CA). A protein stain of the nitrocellulose revealed no differences in amount and pattern of proteins loaded. GFAP immunoreactivity was unaffected by TeNT.

a first series of experiments, astrocytes and NR-GFP cells were incubated in $4.5 \mu \mathrm{M}$ bafilomycin for $1 \mathrm{hr}$. After quisqualate stimulation, 2 of $11 \mathrm{NR}$-GFP cells displayed a single episode of fast kinetic glutamate-mediated currents, and two other cells displayed episodes of bursts of NMDAR channel openings, whereas no activity was observed in the remaining seven NR-GFP cells (Fig. $4 A$ ). In the second group of experiments, a challenge with L-quisqualate (to trigger glutamate release) was applied during the period of bafilomycin incubation. After a second application of L-quisqualate, neither inward current events nor noise increases were observed from NR-GFP recorded cells (Fig. $4 A$ ). The inhibitory effects of bafilomycin were not accompanied by any alteration in the pattern or amplitude of quisqualatemediated $\left[\mathrm{Ca}^{2+}\right]_{\mathrm{i}}$ elevations in astrocytes which, under control conditions, trigger repetitive episodes of glutamate release (Fig. $5 D)$. The activation of NMDARs was not unspecifically affected by bafilomycin because $N R-G F P$ cells $(n=8)$ displayed regular $\left[\mathrm{Ca}^{2+}\right]_{\mathrm{i}}$ elevations after bath application of $200 \mu \mathrm{M}$ NMDA.

\section{DISCUSSION}

Oscillations of the $\left[\mathrm{Ca}^{2+}\right]_{\mathrm{i}}$ represent a widespread mode of signaling in eukaryotic cells (Berridge, 1993). In astrocytes, the main glial population of the $\mathrm{CNS},\left[\mathrm{Ca}^{2+}\right]_{\mathrm{i}}$, oscillations induced by the neurotransmitter glutamate released from activated synapses have been proposed to represent the key aspect of the communication with neurons (Cornell-Bell et al., 1990; Smith, 1994; Pasti et al., 1997). The output of astrocytes in response to this neuronal signaling remains, however, largely undetermined.

The key finding of the present study is that, in cultured astrocytes, activation of AMPA/mGluRs triggers a pulsatile release of glutamate that depends on the frequency of $\left[\mathrm{Ca}^{2+}\right]_{i}$ oscillations. Indeed, the great majority of NMDA receptor-mediated $\left[\mathrm{Ca}^{2+}\right]_{\mathrm{i}}$ elevations in NR-GFP cells (glutamate release biosensors) occurred in temporal correlation with $\left[\mathrm{Ca}^{2+}\right]_{\mathrm{i}}$ increases in neighboring astrocytes. Given that $\left[\mathrm{Ca}^{2+}\right]_{i}$ oscillations of astrocytes from acute brain slices are under the control of neuronal activity (Pasti et al., 1997), it is expected that a pulsatile release of glutamate by astrocytes will follow episodes of high neuronal activity.

Although the frequency of the $\left[\mathrm{Ca}^{2+}\right]_{\mathrm{i}}$ oscillations controls the frequency of the release, the amplitude of the $\left[\mathrm{Ca}^{2+}\right]_{\mathrm{i}}$ increases controls its efficacy. In particular, below an average level of $\left[\mathrm{Ca}^{2+}\right]_{\mathrm{i}}(550 \mathrm{nM})$, the probability of triggering an episode of glutamate release is significantly decreased. It should be stressed that this threshold not only refers to the value recorded in the cell soma (although the release may occur from the processes) but also reflects the average cytosolic values. It is not unlikely that $\left[\mathrm{Ca}^{2+}\right]_{\mathrm{i}}$ increases higher than those measured here may be reached in restricted regions, close to the release sites. Support for this possibility derives from the recent observation that $\mathrm{Ca}^{2+}$ release from the endoplasmic reticulum can result in highly localized $\left[\mathrm{Ca}^{2+}\right]_{\mathrm{i}}$ increase of concentrations $>15 \mu \mathrm{M}$ (Csordas et al., 1999).

The second major conclusion of our work is that the release of glutamate in astrocytes occurs via a mechanism that shares common properties with the exocytosis of glutamate-containing vesicles in neurons. We found that the NMDAR-mediated inward currents elicited by activated astrocytes in NR-GFP cells have kinetic characteristics comparable with those of NMDA currents activated by glutamate released from synaptic terminals. These currents have rise times as fast as $1.5 \mathrm{msec}$, indicating that the activation of the NMDAR in NR-GFP cells is triggered by an abrupt increase in the extracellular concentration of glutamate. The only process known to cause such a rapid increase in concentration of a neurotransmitter is the fusion of vesicles with the plasma membrane.

Currents with slower kinetics (as compared with the kinetics of NMDAR EPSCs) were also recorded. A likely explanation for the variability in current kinetics relies on the geometry of the contacts between stimulated astrocytes and NR-GFP cells. Indeed, the significant degree of correlation observed between rise and decay time values suggests that the distance between the site of glutamate release and the recorded cell determines the time course of the response. The presence of currents with both fast and slow kinetics in the same cell further suggests that glutamate is released either from multiple sites of the same astrocyte and/or from many stimulated astrocytes located at different distances from the recorded NR-GFP cell. The absence of a membrane apposition with a site of release may also account for both the very slow current events and the noise increase resembling bursts of NMDAR channel openings. Currents with slow rise and decay times may, therefore, reflect the kinetics of glutamate diff usion, i.e., slow rising and decaying of glutamate concentration at a given site.

Further evidence in favor of a glutamate release process dependent on vesicle exocytosis derives from the results obtained 

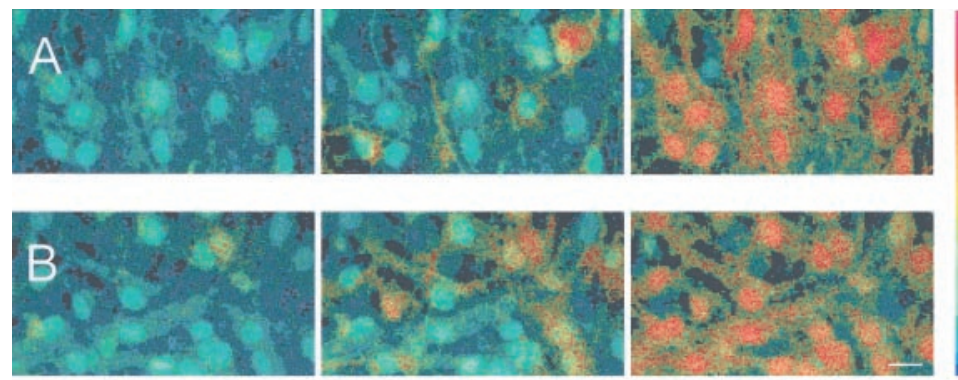

C

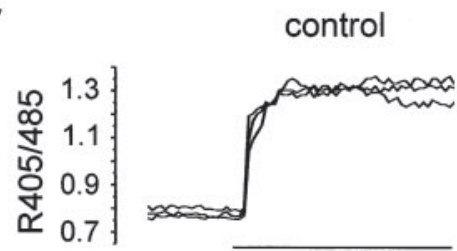

control

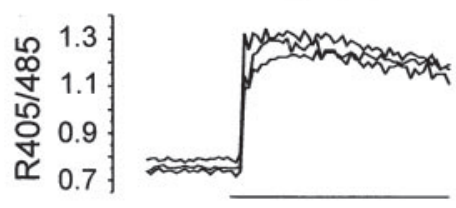

TeNT

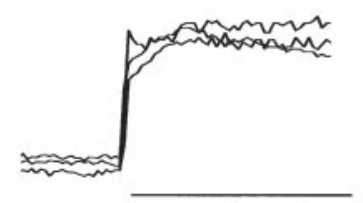

bafilomycin

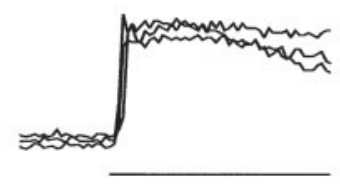

Figure 5. TeNT and bafilomycin do not affect $\left[\mathrm{Ca}^{2+}\right]_{\mathrm{i}}$ elevations triggered in astrocytes by stimulation with L-quisqualate. $A, B$, Sequence of pseudocolor images illustrating the $\left[\mathrm{Ca}^{2+}\right]_{\mathrm{i}}$ increase triggered in indo-1-loaded astrocytes by a challenge with $20 \mu \mathrm{M}$ L-quisqualate in control astrocytes $(A)$ and in astrocytes incubated for $24 \mathrm{hr}$ in TeNT $(B) . C, D$, Kinetics of the $\left[\mathrm{Ca}^{2+}\right]_{\mathrm{i}}$ elevations in three representative astrocytes before and after incubation with either TeNT $(C)$ or bafilomycin $(D)$. The amplitude of $\left[\mathrm{Ca}^{2+}\right]_{\mathrm{i}}$ elevations in response to L-quisqualate stimulation in the different experimental conditions was unchanged $(0.59 \pm 0.01, n=21$ and $0.61 \pm 0.03, n=$ 26, in control astrocytes and after TeNT, respectively; $0.46 \pm$ $0.02, n=74$ and $0.45 \pm 0.02, n=61$, before and after bafilomycin, respectively). Bars indicate the duration of L-quisqualate stimulation. The ratio (405/485) is displayed as a pseudocolor scale.

with TeNT and bafilomycin. These two compounds are known to inhibit neuronal exocytosis by two independent mechanisms: the former through its capacity of selectively proteolysing the v-SNARE protein synaptobrevin (Schiavo et al., 1992; Söllner et al., 1993; Dolly et al., 1994), the latter by inhibiting the v-ATPase that provides the driving force for neurotransmitter accumulation in the secretory vesicles (Bowman et al., 1988; Maycox et al., 1990; Stevens and Forgac, 1997; Araque et al., 2000; Zhou et al., 2000).

As far as TeNT is concerned, its effect is highly specific on the release of glutamate because it did not affect the astrocyte $\mathrm{Ca}^{2+}$ response to AMPA/mGluRs stimulation, while suppressing the $\left[\mathrm{Ca}^{2+}\right]_{\mathrm{i}}$ elevations in the NR-GFP cells. Two aspects of the inhibition by TeNT are worth stressing: (1) unlike in neurons, the inhibition requires several hours of incubation with the toxin, presumably because of lack of specific membrane receptors for TeNT in astrocytes (Bezzi et al., 1998; Verderio et al., 1999); (2) the inhibition of glutamate release was accompanied by cleavage of synaptobrevin. Synaptobrevin is known to be expressed in astrocytes (Parpura et al., 1995; Maienschein et al., 1999), together with other components of the neuronal secretory apparatus, i.e., syntaxin, cellubrevin (Parpura et al., 1995), SNAP-23 (Hepp et al., 1999), and rab3 (Madison et al., 1996; Maienschein et al., 1999).

In the case of bafilomycin, the inhibition of glutamate release is stronger if during the period of preincubation the cells are challenged with agonists. The simplest explanation of this finding is that the drug does not prevent the release of glutamatecontaining vesicles but inhibits their refilling with the transmitter. Similarly to TeNT, bafilomycin affected neither the pattern nor the amplitude of quisqualate-mediated $\left[\mathrm{Ca}^{2+}\right]_{\mathrm{i}}$ elevations in astrocytes. Consistent with our observations, it was recently shown that bafilomycin reduces the slow inward current elicited in neurons by glutamate released from mechanically stimulated astrocytes (Araque et al., 2000). Taken together, the above results indicate that stimulated astrocytes can release glutamate by an exocytotic mechanism similar in its pharmacological sensitivity and, at least in part, in its kinetic characteristics to that of stimulated neurons. A number of important questions remain to be clarified. First of all, given that astrocytes in culture may differ from astrocytes in the intact brain, our observations do not necessarily indicate that astrocytes in situ release glutamate through the same mechanism operative in cultured astrocyte. However, the ability astrocytes from acute brain slices to release glutamate after activation of their GluRs was previously demonstrated (Pasti et al., 1997; Bezzi et al., 1998). In addition, we need the vesicular compartments containing glutamate. In this respect, immunoelectron microscopic analysis revealed that synaptobrevin and synaptophysin are associated with vesicular structures in cultured astrocytes (Maienschein et al., 1999). Furthermore, Calegari et al. (1999) not only have shown that a subpopulation of hippocampal astrocytes in culture possess dense core as well as less dense, smaller vesicles, but they also showed that these cells can release the vesicle-associated protein secretogranin II via a $\mathrm{Ca}^{2+}$-regulated process. Further ultrastructural studies, if possible, combined with immunogold techniques, are necessary to obtain direct evidence for the presence of glutamate-containing vesicles in astrocytes in situ.

Despite these general similarities with the neuronal glutamatecontaining vesicles, it is also clear that the astrocyte compartment containing the neurotransmitter may significantly differ from the neuronal one, at least in the mechanism of glutamate accumulation. In fact, because of the high glutamine synthetase activity in astrocytes, it is predicted that the cytoplasmic glutamate concentration should be much lower in astrocytes than in neurons. The kinetic characteristics of the vesicular transporter for the neurotransmitter might be accordingly quite distinct in the two cell types. more information on the cellular and molecular characteristics of 
The physiological consequences of the exocytotic release of glutamate from astrocytes on neuronal function remain to be investigated. If such a release occurs through an exocytotic mechanism, it will have effects on neurons far more complex than those suggested on the basis of the available data.

In summary, our results demonstrate that the release of glutamate by astrocytes results in a fast activation of the NMDAR in the sensor cells. Moreover, this activation depends on the functional integrity of synaptobrevin as well as of v-ATPase. These data are consistent with the presence of a regulated, secretory pathway for glutamate-containing vesicles under the control of $\left[\mathrm{Ca}^{2+}\right]_{\mathrm{i}}$ oscillations. Our findings add a new level of spatial and temporal complexity to the action of glutamate in the brain and hint at the existence of a regulated, vesicle-mediated glutamatergic communication between astrocytes and neurons.

\section{REFERENCES}

Araque A, Parpura V, Sanzgiri RP, Haydon PG (1998a) Glutamatedependent astrocyte modulation of synaptic transmission between cultured hippocampal neurons. Eur J Neurosci 10:2129-2142.

Araque A, Sanzgiri RP, Parpura V, Haydon PG (1998b) Calcium elevation in astrocytes causes an NMDA receptor-dependent increase in the frequency of miniature synaptic currents in cultured hippocampal neurons. J Neurosci 18:6822-6829.

Araque A, Li N, Doyle RT, Haydon PG (2000) SNARE proteindependent glutamate release from astrocytes. J Neurosci 20:666-673.

Berridge MJ (1993) Inositol triphosphate and calcium signaling. Nature $361: 315-325$.

Bezzi P, Carmignoto G, Pasti L, Vesce S, Rossi D, Lodi Rizzini B, Pozzan T, Volterra A (1998) Prostaglandins stimulate calciumdependent glutamate release in astrocytes. Nature 391:281-285.

Bowman EJ, Siebers A, Altendorf K (1988) Bafilomycins: a class of inhibitors of membrane ATPases from microorganisms, animal cells and plant cells. Proc Natl Acad Sci USA 85:7972-7976.

Calegari F, Coco S, Taverna E, Bassetti M, Verderio C, Corradi N, Matteoli M (1999) A regulated secretory pathway in cultured hippocampal astrocytes. J Biol Chem 274:22539-22547.

Carmignoto G, Vicini S (1992) Activity-dependent decrease in NMDA receptor responses during development of the visual cortex. Science 258:1007-1011.

Carmignoto G, Pasti L, Zonta M, Pozzan T, Vicini S (1999) $\left[\mathrm{Ca}^{2+}\right]_{\mathrm{i}}$ oscillations in astrocytes regulate a fast, quantal-like release of glutamate. Soc Neurosci Abstr 25:17 12 .

Collingridge GL, Herron CE, Lester RAJ (1988) Synaptic activation of $N$-methyl-D-aspartate receptors in the Schaffer collateral-commissural pathway of rat hippocampus. J Physiol (Lond) 399:283-300.

Cornell-Bell AH, Finkbeiner SM, Cooper MS, Smith SJ (1990) Glutamate induces calcium waves in cultured astrocytes: long range glial signaling. Science 247:470-473.

Csordas G, Thomas AP, Hajnoczky G (1999) Quasi-synaptic calcium signal transmission between endoplasmic reticulum and mitochondria. EMBO J 18:96-108.

Dani JW, Chernjavsky A, Smith SJ (1992) Neuronal activity triggers calcium waves in hippocampal astrocyte network. Neuron 8:429-440.

Dolly JO, de Paiva A, Foran P, Lawrence G, Daniels-Holgate P, Ashton AC (1994) Probing the process of transmitter release with botulinum and tetanus neurotoxins. Semin Neurosci 6:149-158.

Hamill OP, Marty A, Neher E, Sakmann B, Sigworth FJ (1981) Improved patch-clamp technique for high-resolution current recording from cells and cell-free membrane patches. Pflügers Arch 391:85-100.

Hassingher T, Atkinson PB, Stricker GJ, Whale LR, Dudek FE, Kossel AH, Kater SB (1995) Evidence for glutamate-mediated activation of hippocampal neurons by glial calcium waves. J Neurobiol 28:159-170.

Hepp R, Perraut M, Chasserot-Golaz S, Galli T, Aunis D, Langley K, Grant JLN (1999) Cultured glial cells express the SNAP-25 analogue SNAP-23. Glia 27:181-187.

Kang J, Jiang L, Glodman SA, Nedergaard M (1998) Astrocytemediated potentiation of inhibitory synaptic transmission. Nat Neurosci 1:683-692.
Kimelberg HK, Goderie SK, Higman S, Waniewski RA (1990) Swelling-induced release of glutamate, aspartate, and taurine from astrocyte cultures. J Neurosci 10:1583-1591.

Laemmli UK (1970) Cleavage of structural proteins during the assembly of the head of bacteriophage T4. Nature 227:680-685.

Lester RAJ, Jahr CE (1992) NMDA channel behaviour depends on agonist affinity. J Neurosci 12:635-643.

Lester RAJ, Clements JD, Westbrook GL, Jahr CE (1990) Channel kinetics determine the time course of NMDA-receptor mediated synaptic currents. Nature 346:565-567.

Madison DL, Kruger WH, Kim T, Pfeiffer SE (1996) Differentail expression of rab3 isoforms in oligodendrocytes and astrocytes. J Neurosci Res 45:258-268.

Maienschein V, Marxen N, Volknandt W, Zimmermann H (1999) A plethora of presynaptic proteins associated with ATP-storing organelles in cultured astrocytes. Glia 26:233-244.

Martin DL (1992) Synthesis and release of neuroactive substances by glia cells. Glia 5:81-94.

Maycox PR, Hell JW, Jahn R (1990) Amino acid neurotransmission: spotlight on synaptic vesicles. Trends Neurosci 13:83-87.

Newman EA, Zahs KR (1998) Modulation of neuronal activity by glial cells in the retina. J Neurosci 18:4022-4028.

Parpura V, Basarky TA, Liu F, Jeftinija K, Jeftinija S, Haydon PG (1994) Glutamate-mediated astrocyte-neuron signaling. Nature 369:744-747.

Parpura V, Fang Y, Basarky TA, Jahn R, Haydon PG (1995) Expression of synaptobrevin II, cellubrevin and syntaxin but not SNAP-25 in cultured astrocytes. FEBS Lett 377:489-492.

Pasti L, Pozzan T, Carmignoto G (1995) Long-lasting changes of calcium oscillations in astrocytes. A new form of glutamate-mediated plasticity. J Biol Chem 25:15203-15210.

Pasti L, Volterra A, Pozzan T, Carmignoto G (1997) Intracellular calcium oscillations in astrocytes: a highly plastic, bidirectional form of communication between neurons and astrocytes in situ. J Neurosci 17:7817-7830.

Pfrieger FW, Barres BA (1996) New views on synapse-glia interactions. Curr Opin Neurobiol 6:615-621.

Porter JT, McCarthy KD (1996) Hippocampal astrocytes in situ respond to glutamate released from synaptic terminals. $J$ Neurosci 16:5073-5081.

Prasher DC, Eckenrode VK, Ward WW, Prendergast FG, Cormier MJ (1992) Primary structure of the Aequorea victoria green fluorescent protein. Gene 111:229-233.

Rizzuto R, Brini M, Pizzo P, Murgia M, Pozzan T (1995) Chimeric green fluorescent protein: a new tool for visualizing subcellular organelles in living cells. Curr Biol 5:635-642.

Rossetto O, Gorza L, Schiavo L, Schiavo N, Scheller RH, Montecucco C (1996) VAMP/synaptobrevin isoforms 1 and 2 are widely and differentially expressed in non neuronal tissues. J Cell Biol 132:167-179.

Scheenen JJM, Hofer AN, Pozzan T (1998) Intracellular measurements of calcium using fluorescent dyes. In: Cell biology. A laboratory handbook. Vol 3 (Celis JE, ed), pp 363-374. San Diego: Academic.

Schiavo G, Benfenati F, Poulain B, Rossetto O, Polverino de Laureto P, DasGupta BR, Montecucco C (1992) Tetanus and botulinum-B neurotoxins block neurotransmitter release by proteolitic cleavage of synaptobrevin. Nature 359:832-834.

Smith SJ (1994) Neuromodulatory astrocytes. Curr Biol 4:807-810.

Söllner T, Bennet MK, Whiteheart SW, Scheller RH, Rothman JE (1993) A protein assembly-disassembly pathway in vitro that may correspond to sequential steps of synaptic vesicle docking, activation and fusion. Cell 75:409-418.

Stevens TH, Forgac M (1997) Structure, function and regulation of the vacuolar $\left(\mathrm{H}^{+}\right)$-ATPase. Annu Rev Cell Dev Biol 13:779-808.

Szatkowski M, Barbour B, Attwell D (1990) Non-vesicular release of glutamate from glial cells by reversed electrogenic glutamate uptake. Nature 3489:443-447.

Verderio C, Coco S, Rossetto O, Montecucco C, Matteoli M (1999) Internalization and proteolytic action of botulinum toxins in CNS neurons and astrocytes. J Neurochem 73:372-379.

Vicini S, Wang JF, Li JH, Zhu WJ, Wang YH, Luo JH, Wolfe BB, Grayson DR (1998) Functional and pharmacological differences between recombinant NMDA receptors. J Neurophysiol 79:555-566.

Zhou Q, Petersen CCH, Nicoll RA (2000) Effects of reduced vesicular filling on synaptic transmission in rat hippocampal neurons. J Physiol (Lond) 525:195-206. 